\title{
集成光纤的微流控电泳芯片制作技术
}

\author{
李孟春 \\ (太原理工大学应用物理系, 太原 030024. E-mail: limengchun75@163.com)
}

\begin{abstract}
摘要 利用印刷电路板技术制作芯片模具, 以 PDMS 为材料制成微流控电泳芯片. 该芯片上集成有光 纤, 靠光纤传输激发光, 使激发光斑的大小与微流控沟道的深度尺寸相接近, 提高了检测灵敏度, 省去 了光学聚焦系统. 对集成光纤的微流控电泳芯片的加工工艺和封装方法进行了探讨. 用所制作的芯片 对 FITC(异硫氰酸苂光素)和以 FITC 标记的氨基酸进行了分离, 结果证明了该芯片的可行性.
\end{abstract}

关键词 聚二甲基硅氧烷(PDMS) 光纤 微流控芯片 制作技术

微流控芯片电泳技术是一种新兴的生化分析技 术，并已广泛应用于DNA、氨基酸、蛋白质、有机分 子及无机离子等物质的分析和检测. 目前各种微流 控电泳芯片的研制都处在一个比较热的发展阶段, 在众多的微流控电泳芯片中，集成光纤的微流控电 泳芯片由于其特有的结构逐渐引起人们的注意. 这 种芯片是把光纤集成在芯片上, 用光纤作为传光介 质, 靠光纤端面发出的微小光斑激发微沟道中用苂 光物质标记的生物样品来产生苂光信号. 将光纤集 成在芯片上已有文献报道 ${ }^{[1]}$, 但对于光纤中心与微 沟道中心对准的问题却很少提及 ${ }^{[2]}$.

制作微流控电泳芯片时, 通常应用的是光刻掩 模技术, 这需要特殊的设备来完成, 所以制作成本较 高. 目前, 国外已经将印刷电路板技术应用到微沟道 的制作 ${ }^{[3]}$, 即利用印刷电路板上两个相对的铜线间 的空间作为微沟道, 然后对微沟道进行封装制成微 芯片. 由于封装后的微沟道四个壁的材料不完全相 同, 其表面电荷密度也就不尽相同 ${ }^{[4]}$, 所以在电泳分 离过程中会出现分离谱带展宽的现象.

本研究采用印刷电路板技术制作了盖片模具和 基片模具, 在此基础上以聚二甲基硅氧烷(PDMS)为 材料制成了集成光纤的微流控电泳芯，该芯片的盖 片和基片上都有 PDMS，使整个微流控沟道的材料保 持一致, 增加了芯片的密封效果, 提高了电泳分离效 率.

\section{1 微流控芯片的制作}

集成光纤的微流控电泳芯片的制作过程主要包 括两部分: 印刷电路板模具的制作及 PDMS 基片和
盖片的制作.

印刷电路板模具主要由电路板加工公司来完成. 微流控电泳芯片的制备就是靠印刷电路板上凸起的 铜皮“复制”出芯片上的沟道. 印刷电路板上的铜皮 厚度一般都是相同的，而为了使将来制成芯片上的 微沟道中心和光纤中心对准, 基片模具上微流控沟 道的铜皮和光纤沟道的铜皮厚度不相同, 这就需要 在制作电路板时进行特殊声明. 加工的基片模具和 盖片模具如图 1 所示, 基片上微沟道铜皮厚度为 50 $\mu \mathrm{m}$, 光纤沟道铜皮厚度为 $90 \mu \mathrm{m}$; 盖片上的光纤沟道 铜皮厚度为 $40 \mu \mathrm{m}$.
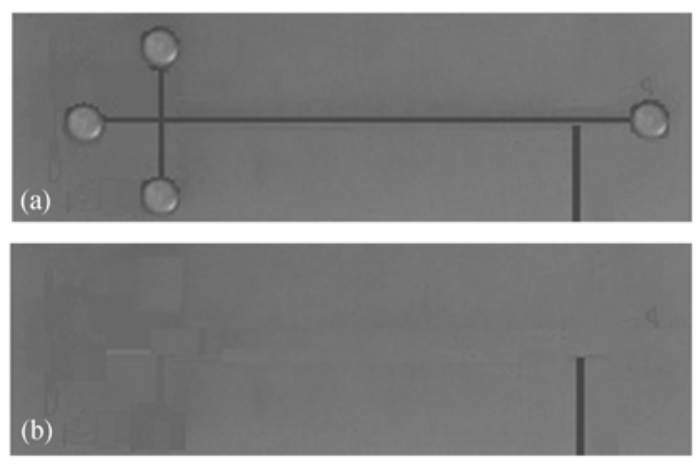

图 1 基片模具(a)和盖片模具(b)

芯片的制作流程与文献 [5]报道的相类似，整个 制作过程示意图如图 2 所示. 图 3 为芯片的示意图.

\section{2 实验与讨论}

\section{1 芯片的放置}

进行实验时, 把芯片放在特制的暗室中, 暗室底 


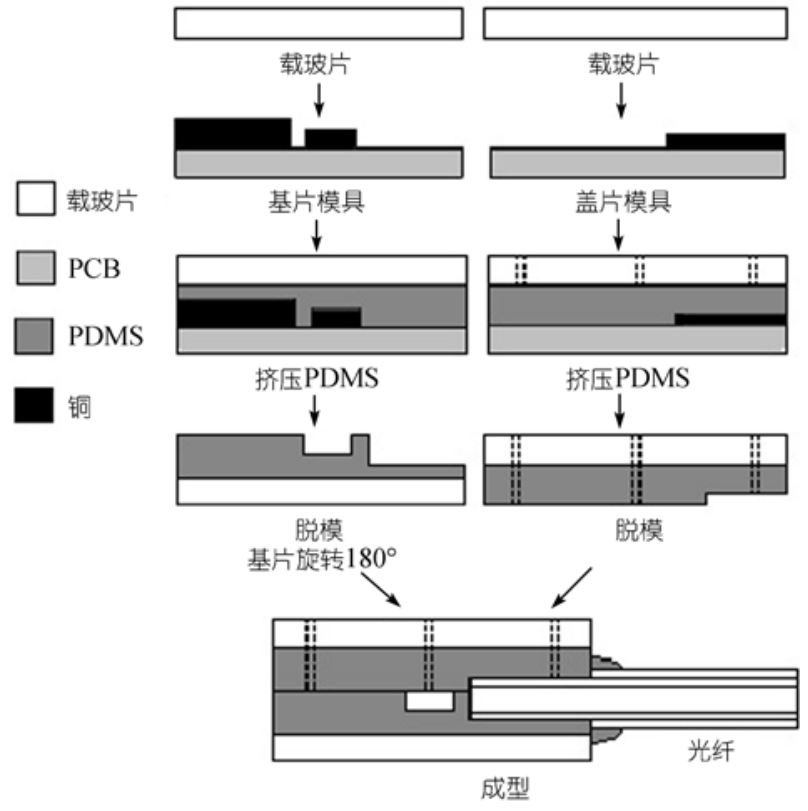

图 2 芯片的制作过程示意图

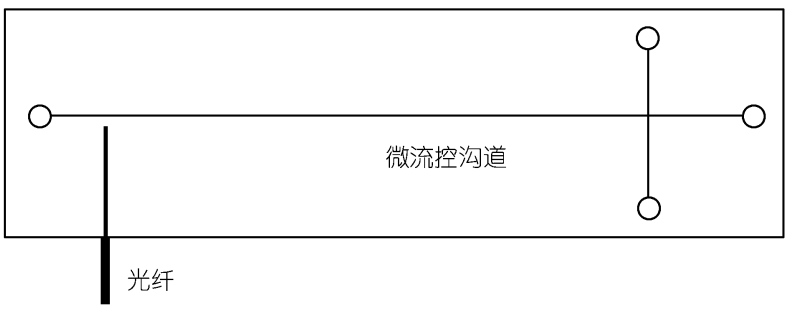

图 3 芯片示意图

部有一个比芯片稍大的凹槽, 用来固定芯片, 凹槽中 有一个直径为 $3 \mathrm{~mm}$ 的小圆孔正对着暗室下方的光电 倍增管, 光纤与沟道的交叉部分刚好放置在小圆孔 的上方, 芯片中被激发的苂光信号可以通过该小圆 孔并经滤光片滤光和凸透镜会聚后到达光电倍增管, 光电倍增管所加的电压为 $650 \mathrm{~V}$. 暗室侧壁有高压导 线和光纤接口, 用中心波长为 $470 \mathrm{~nm}$ 的蓝色发光二 极管作为激发光源, 经耦合装置引入光纤. 光电倍增 管输出信号经过单片机电路处理后由串口送入计算 机. 如图 4 所示.

\subsection{LED 光束与光纤的耦合}

由于LED为非相干光源, 其光束的发散角比较 大. 如果LED直接与纤芯只有 $62.5 \mu \mathrm{m}$ 的光纤耦合, 耦合效率将非常低, 采用光纤准直器能够显著提高 它们的耦合效率. 光纤准直器是由尾纤与自聚焦透 镜(渐变折射率棒透镜)精确定位而成, 可将光纤内传
输的光转变成准直光(平行光), 或者将外界的平行光 耦合到光纤内 [6]. 芯片上的光纤与光纤准直器上的 尾纤各自接有裸光纤适配器, 然后通过法兰盘与其 进行连接, 如图 5 所示.

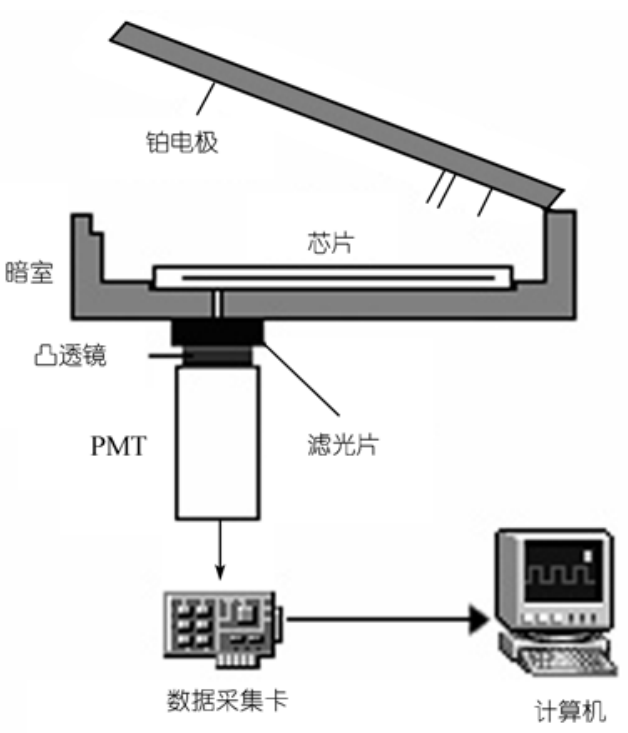

图 4 芯片的放置

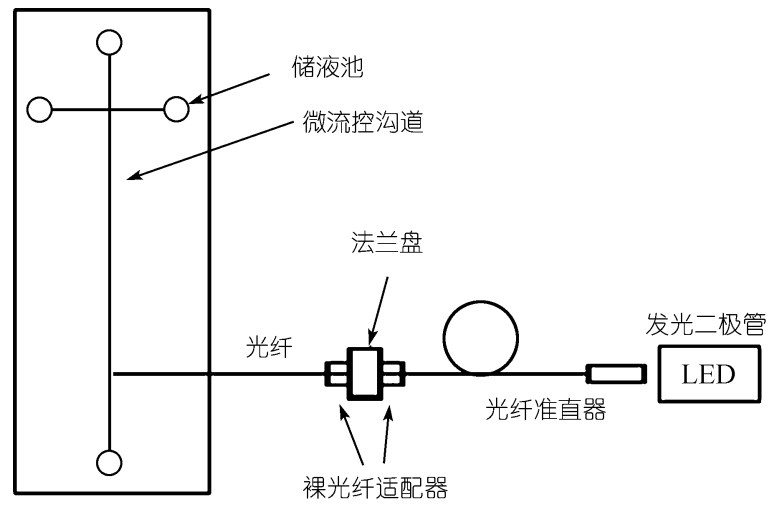

图 5 微流控芯片及光的耦合

\section{3 光纤与微流控沟道之间的距离}

芯片上微流控沟道的深度为 $50 \mu \mathrm{m}$, 而光纤纤芯 的直径为 $62.5 \mu \mathrm{m}$, 光纤所发出的光在到达微流控沟 道前还要有一定的发散, 发散角的大小由光纤的数 值孔径 $N A$ 来决定, 即 $N A=n \sin \theta^{[7]}, n$ 代表光纤与微流 控沟道之间的传播介质PDMS的折射率. 这里所用的 多模光纤的数值孔径为 0.22 , PDMS的折射率为 1.43 , 所以这个角度 $\theta$ 等于 $8.85^{\circ}$, 则照射到微流控沟道上 的光斑直径的大小可以粗略地根据 $w=D+2 x \tan \theta$ 得到, 
其中 $D$ 为光纤的直径, $x$ 为光纤端面与微流控沟道之 间的距离, 该值为 $100 \mu \mathrm{m}$, 所以 $w$ 的大小为 $93 \mu \mathrm{m}$, 这个值小于文献 [8]中的 $160 \mu \mathrm{m}$. 用该芯片对浓度为 $50 \mathrm{ng} / \mu \mathrm{L}$ 的 $\varphi$ X174/HaeIII DNA markers(72, 118, 194, $234,271,281,310,603,872,1078$ 和 $1353 \mathrm{bp} 11$ 个片 段)进行电泳分离, 当光电倍增管所加的电压为 650 $\mathrm{V}$ 、分离电压为 $300 \mathrm{~V} / \mathrm{cm}$ 时, 11 个片段中差别比较小 的 271 和 281 都得到了完全分离. 所以我们认为光纤 与微流控沟道之间的距离已经满足对普通生物试剂 的分离要求.

\section{4 性能考察}

用发光二极管作为激发光源, 以异硫氰酸苂光 素(FITC)作为检测物质对该芯片进行考察，结果显示: 检测极限达到 $1.3 \times 10^{-7} \mathrm{~mol} / \mathrm{L}$, 信噪比 $\mathrm{S} / \mathrm{N}=5$; 在 1.8 $\times 10^{-7} \sim 4.2 \times 10^{-5} \mathrm{~mol} / \mathrm{L}$ 范围内相关系数为 $0.996(n=6)$. 用 $2.0 \times 10^{-6} \mathrm{~mol} / \mathrm{L}$ 的FITC共做了 6 次重复电泳实验, 其峰值面积、峰高以及迁移时间重复性比较好, 从数 据采集软件上的自动寻峰和对曲线积分等功能可以 发现上面三个参数的变异系数均小于 $5 \%$. 该性能与 用溴铇灯作为激发光源的检测结果相当 ${ }^{[9]}$, 可以满 足一般的测试需求, 能够用于普通生物样品的分析. 图 6 是用硼酸 $\left(2.0 \times 10^{-2} \mathrm{~mol} / \mathrm{L}, \mathrm{pH} 9.2\right)$ 为缓冲液, 以 3

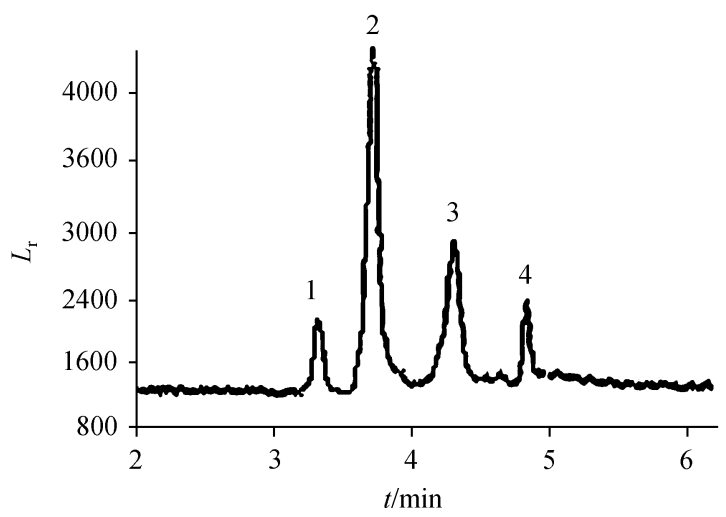

图 6 氨基酸电泳图

1, 精氨酸(arginine); 2, 异硫氬酸苂光素(FITC); 3, 甘氨酸(glycine); 4 , 苯丙氨酸(phenylalanine) $\mathrm{mol} / \mathrm{L}$ FITC 标记的氨基酸电泳图. 横坐标表示分离 阶段所用的时间, 纵坐标 $I_{\mathrm{r}}$ 表示苂光信号的相对光强. 从图中看出基线噪声比较高, 已经达到 1200 左右, 这是因为发光二极管发出光的波长范围比较大, 有 一部分光可以经过滤光片直接被光电倍增管放大.

\section{3 结论}

本文探讨了集成光纤的微流控电泳芯片的工作 原理以及制作过程, 以发光二极管作为激发光源, 用 异硫氰酸苂光素和异硫氰酸苂光素标记的氨基酸考 察了芯片的性能, 实验验证了该芯片的可行性. 由于 发光二极管为非相干光源, 亮度比较低, 所以芯片的 检出限不如用激光作为激发光源那样低, 但随着超 高亮度发光二极管的不断商品化, 提高 LED 与光纤 之间的耦合效率，芯片的检出限还能进一步降低.

\section{参考文献}

1 Chabinyc M L, Chiu D T, McDonald J C, et al. An integrated fluorescence detection system in poly(dimethylsiloxane) for microfluidic applications. Anal Chem, 2001, 73(18): 4491-4498[DOI]

2 Fu L M, Yang R J, Lin C H, et al. Electrokinetically driven micro flow cytometers with integrated fiber optics for on-line cell/particle detection. Analytica Chimica Acta, 2004, 507(1): 163-169[DOI]

3 Merkel T, Pagel L, Glock H-W. Electric fields in fluidic channels and sensor applications with capacitance. Sensor Actuat A-Phys, 2000, 80(1): 1-7[DOI]

4 Sanders J C, Breadmore M C, Mitchell P S, et al. A simple PDMS-based electro-fluidic interface for microchip electrophoretic separations. Analyst, 2001, 127(12): 1558-1563[DOI]

5 Zhang C X, Manz A. Narrow sample channel injectors for capillary electrophoresis on microchips. Anal Chem, 2001, 73(11): 26562662[DOI]

6 崔三烈. 光纤传感器原理与应用技术. 哈尔滨: 哈尔滨工程大学 出版社, 1995. 13-20

7 吴德明. 光纤通信原理与技术. 北京: 科学出版社, 2004. 8-15

$8 \mathrm{Li} \mathrm{H} \mathrm{F}$, Lin J M, Su R G, et al. A compactly integrated laser-induced fluorescence detector for microchip electrophoresis. Electrophoresis, 2004, 25(12): 1907-1915 [DOI]

9 熊少祥, 李建军, 程介克. 高效毛细管电泳一电荷耦合器件检 测器联用技术研究. VI. 激光诱导苂光检测装置及与普通光源装 置的比较. 分析科学学报, 1995, 11(3): 12-15 